\title{
Mycotic Abdominal Aortic Aneurysm in the Endovascular Era
}

Ian P. Barry ${ }^{1}$

1. Vascular and Endovascular Surgery, Fiona Stanley Hospital, Perth, AUS

Corresponding author: Ian P. Barry, ian.barry@health.wa.gov.au

\begin{abstract}
A mycotic aneurysm is a localised dilatation of an artery due to destruction of the vessel wall by infection. Diagnosis is based on clinical, microbiological, and radiological findings. Typical management includes antibiotic therapy and open surgical debridement with or without revascularisation. This case of mycotic aortic aneurysm highlights the utilisation of endovascular grafts in the treatment of such pathology. This may improve both short and long term morbidity and mortality as compared to open intervention.
\end{abstract}

Categories: Cardiac/Thoracic/Vascular Surgery, Radiology, Infectious Disease

Keywords: mycotic aneurysm, aneurysm, salmonella, aortitis, endovascular aneurysm repair (evar), evar, pseudoaneurysm, aortic aneurysm

\section{Introduction}

A mycotic aneurysm is a localised dilatation of an artery due to destruction of the vessel wall by infection [1]. It may be classified as true (involving all three layers of the arterial wall) or false (collection of blood that forms between the two outer layers of an artery) [1]. It may occur due to a pre-existing aneurysm becoming secondarily infected or infection of the arterial wall resulting in the development of a new aneurysm. Risk factors include antecedent infection, arterial injury, and impaired immunity [2-4]. In the setting of local arterial wall infection, localised perforation and pseudo aneurysm may result.

The organisms with the greatest affinity for the aortic wall are Staphylococcus and Salmonella spp. [5]. Salmonella is less prevalent in comparison but has been reported in up to $15 \%$ of cases with bacteremic seeding of atherosclerotic plaque proposed [6-7].

Typical management includes antibiotic therapy and open surgical debridement with or without revascularisation [8]. However, endovascular techniques are now being utilised as a treatment alternative to avoid the high morbidity and mortality associated with open aortic surgery.

Received 11/04/2019

Review began 11/05/2019 Review ended 11/10/2019 Published 11/11/2019

๑) Copyright 2019

Barry. This is an open access article distributed under the terms of the Creative Commons Attribution License CC-BY 3.0., which permits unrestricted use, distribution, and reproduction in any medium, provided the original author and source are credited.

\section{Case Presentation}

An 82-year-old male presented to his local hospital with mild chest pain whereby he was given a diagnosis of pericarditis and discharged home. At this stage, discomfort predominantly affected his lower abdomen and lumbar spine with minimal radiation to the medial thigh. Ongoing subjective fevers, lethargy, and nausea led to re-presentation to his local emergency department. Nil other infective symptoms were highlighted with the patient denying any recent cough, dysuria, or diarrhoea.

On examination, he was noted to be tachycardic at $110 \mathrm{bpm}$ with a temperature of 38.5 degrees (Celsius). Abdominal palpation revealed suprapubic tenderness without evidence of peritonism. No arterial compromise was identified to the bilateral lower limbs.

Laboratory investigations revealed a white cell count of $12.27 \times 10^{\wedge} 9 / \mathrm{L}$ (normal range $4-11 \times 10^{\wedge} 9 / \mathrm{L}$ ) with a c-reactive protein (CRP) of $240 \mathrm{mg} / \mathrm{L}$ (normal range $<5 \mathrm{mg} / \mathrm{L}$ ). Blood cultures were sent and broad-spectrum antibiotics were commenced (as per local hospital guidelines). Urgent contrast-enhanced computed tomography (CT) of the abdomen and pelvis was performed. This highlighted the aneurysmal dilatation of the aortic bifurcation extending into both common iliac arteries with retroperitoneal inflammatory fatstranding (Figure 1). 


\section{Cureus}

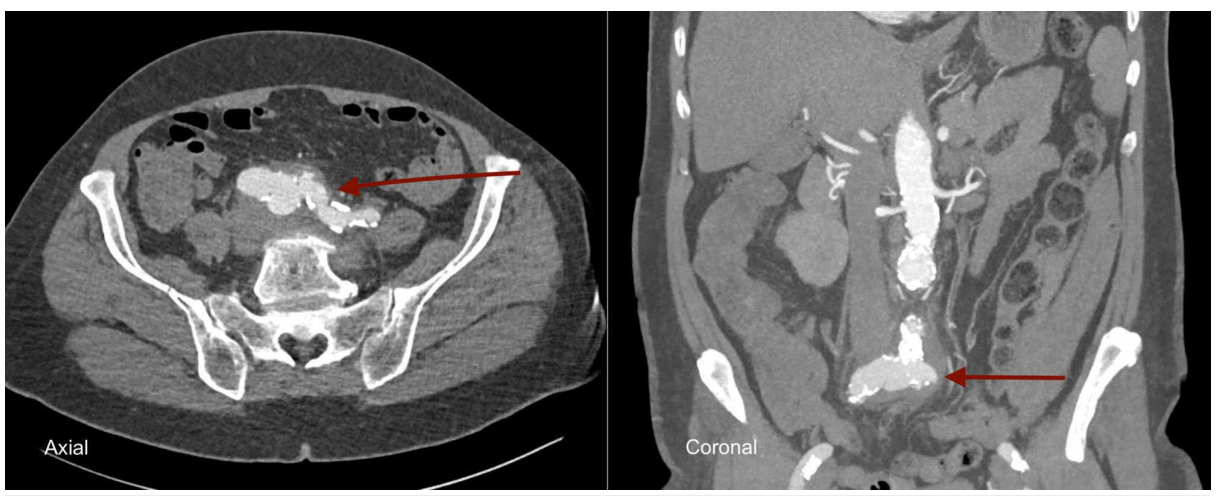

FIGURE 1: Mycotic aneurysm of aortic bifurcation (axial and coronal contrast-enhanced computed tomography)

He was emergently transferred to a tertiary hospital where he could receive specialist care. Blood cultures grew Salmonella spp. with the subsequent rationalisation of his antibiotic regimen. A multi-disciplinary approach was utilised in the development of an appropriate management strategy with vascular surgery, microbiology, and infectious diseases involved. In light of the anatomical considerations, as well as the high morbidity and mortality associated with open surgical repair, endovascular intervention with lifelong antibiotic therapy was proposed.

The patient consented to endovascular aortic aneurysm repair (EVAR) with a Gore Excluder infra-renal stent (WL Gore and Associates, Flagstaff, AZ) (26 x 14 x 140 mm) and bilateral internal iliac artery (IIA) embolization via amplatzer plugs ( 9 x $16 \mathrm{~mm}$ and $9 \times 14 \mathrm{~mm}$ ). Embolisation of the IIA's was undertaken to ensure an adequate seal and to avoid the development of an endoleak which was absent on the completion angiogram (Figure 2).

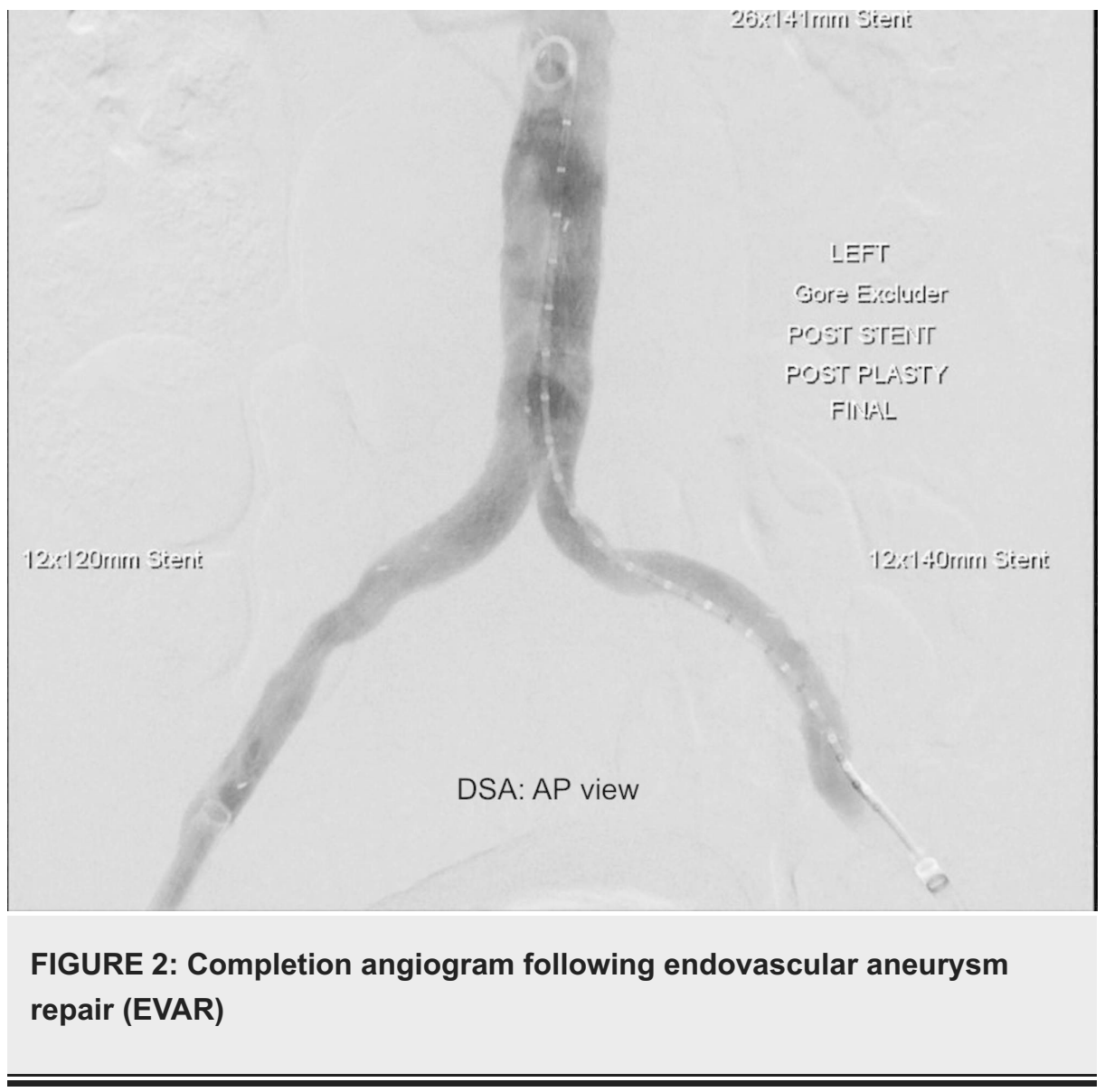

Following this, he returned to the ward and had an uncomplicated post-operative course. He was discharged home on day three following EVAR with ongoing intravenous antibiotics and specialist infectious disease 


\section{Discussion}

Abdominal aortic aneurysms of non-infective or non-inflammatory origin have been managed via endovascular means, where appropriate, for many years (imaging plays an essential role in the delineation of these pathologies with this case highlighting several mycotic features including multi-lobulated appearance and peri-aortic inflammation). However, the utilisation of such techniques in mycotic aortic aneurysm is in its infancy. There are no randomised control trials to guide the management of such aneurysms with strategies predominantly based upon clinical experience and case series.

Endovascular therapy may therefore offer an alternative treatment modality, specifically for those where comorbidity precludes open aortic surgery. This was highlighted by Kan et al. with a 90\% 30-day survival and an $82 \%$ two-year survival identified in those who underwent endovascular repair for mycotic thoracic or abdominal aortic aneurysms [9]. A Swedish study also highlighted significantly reduced perioperative mortality in those treated endovascularly as compared to open surgical repair (three-month survival; $96 \%$ versus $74 \%$ ) with comparable long term outcomes [10].

A mycotic aortic aneurysm is a life-threatening condition and the ongoing development of endovascular grafts aligned to the ever increasing surgical expertise may improve both short and long term outcomes. This case highlights the low peri-operative morbidity/mortality associated with such interventions.

\section{Conclusions}

Salmonella aortitis/mycotic aneurysm is a rare condition which may rapidly progress to pseudo aneurysm formation and rupture. It is important to recognise this condition so prompt treatment may be initiated. Diagnosis is based on clinical, microbiological, and radiological findings. Optimal treatment strategies require further investigation. This case demonstrates the symptoms and signs, aetiology, and radiological findings of a mycotic abdominal aortic aneurysm as well as the effective utilisation of endovascular techniques in acute management.

\section{Additional Information \\ Disclosures}

Human subjects: Consent was obtained by all participants in this study. Conflicts of interest: In compliance with the ICMJE uniform disclosure form, all authors declare the following: Payment/services info: All authors have declared that no financial support was received from any organization for the submitted work. Financial relationships: All authors have declared that they have no financial relationships at present or within the previous three years with any organizations that might have an interest in the submitted work. Other relationships: All authors have declared that there are no other relationships or activities that could appear to have influenced the submitted work.

\section{References}

1. Overview of infected (mycotic) arterial aneurysm . (2019). Accessed: November 2, 2019: https://www.uptodate.com/contents/overview-of-infected-mycotic-arterial-aneurysm.

2. Dieter RA: Dental mycotic abdominal aneurysm. J Am Coll Surg. 2005, 201:650. https://doi.org/10.1016/j.jamcollsurg.2005.06.256

3. Qureshi T, Hawrych AB, Hopkins NF: Mycotic aneurysm after percutaneous transluminal femoral artery angioplasty. J Roy Soc Med. 1999, 92:255-256. https://doi.org/10.1177/014107689909200515

4. Gunst JD, Jensen-Fangel S: A mycotic abdominal aortic aneurysm caused by Listeria monocytogenes in a patient with HIV infection. BMJ Case Rep. 2014, http://dx.doi.org/10.1136/bcr-2013-202712

5. Brossier J, Lesprit P, Marzelle J, Allaire E, Becquemin JP, Desgranges P: New bacteriological patterns in primary infected aorto-iliac aneurysms: a single-centre experience. Eur J Vasc Endovasc Surg. 2010, 40:582588. https://doi.org/10.1016/j.ejvs.2010.07.020

6. Moneta GL, Taylor LM Jr, Yeager RA, Edwards JM, Nicoloff AD, McConnell DB, Porter JM: Surgical treatment of infected aortic aneurysm. Am J Surg. 1998, 175:396-399. https://doi.org/10.1016/S0002-9610(98)00056-7

7. Hsu RB, Tsay YG, Wang SS, Chu SH: Surgical treatment for primary infected aneurysm of the descending thoracic aorta, abdominal aorta, and iliac arteries. J Vasc Surg. 2002, 36:746-750. https://doi.org/10.1067/mva.2002.126557

8. Reddy DJ, Shepard AD, Evans JR, Wright DJ, Smith RF, Ernst CB: Management of infected aortoiliac aneurysms. Arch Surg. 1991, 126:873-878. https://doi.org/10.1001/archsurg.1991.01410310083012

9. Kan CD, Lee HL, Yang YJ: Outcome after endovascular stent graft treatment for mycotic aortic aneurysm: a systematic review. J Vasc Surg. 2007, 46:906-912. https://doi.org/10.1016/j.jvs.2007.07.025

10. Sörelius K, Wanhainen A, Furebring M, Björck M, Gillgren P, Mani K: Nationwide study of the treatment of mycotic abdominal aortic aneurysms comparing open and endovascular repair. Circulation. 2016, 134:18221832. https://doi.org/10.1161/CIRCULATIONAHA.116.024021 